Synthesis Alerts is a monthly feature to help readers of Synthesis keep abreast of new reagents, catalysts, ligands, chiral auxiliaries, and protecting groups which have appeared in the recent literature. Emphasis is placed on new developments but established reagents, catalysts etc are also covered if they are used in novel and useful reactions. In each abstract, a specific example of a transformation is given in a concise format designed to aid visual retrieval of information.

Synthesis Alerts is a personal selection by:

Stephen Brand, John Christopher, Emma Guthrie, Philip Kocienski, Louise Lea, Russell McDonald, Graeme McAllister and Robert Narquizian of Glasgow University.

Georg Thieme Verlag does not accept responsibility for the accuracy, content, or selection of the data.
The journals regularly covered by the abstractors are:

Angewandte Chemie International Edition

Bulletin of the Chemical Society of Japan

Chemical Communications

Chemistry A European Journal

Chemistry Letters

European Journal of Organic Chemistry

Helvetica Chimica Acta

Heterocycles

Journal of the American Chemical Society

Journal of Organic Chemistry

Organometallics

Perkin Transactions 1

Synlett

Synthesis

Tetrahedron

Tetrahedron Asymmetry and Tetrahedron Letters

Article Identifier:

1437-210X,E;1999,0,05,0898,0903,ftx,en;X00599SS.pdf

(S)-2,2'-Binaphthoyl-( $R, R)$-di(1-phenylethyl)am inoylphosphine

A mediates enantioselective 1,4-addition of $\omega$-functionalised zinc reagents to a variety of cyclohexenones. Subsequent aldol condensation of the liberated aldehydes led to bicyclo[4.4.0] decalones with high stereoselectivity.

R. Naasz, L. A. Arnold, M. Pineschi, E. Keller, B. L. Feringa J. Am. Chem. Soc. 1999, 121, 1104.

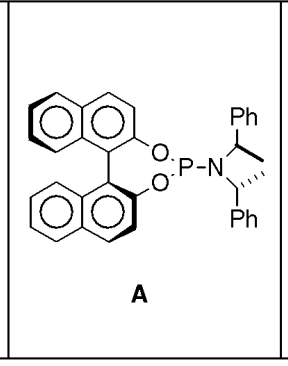

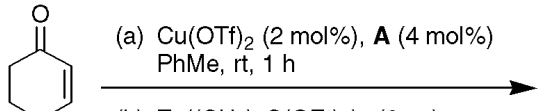

(b) $\mathrm{Zn}\left(\left(\mathrm{CH}_{2}\right)_{3} \mathrm{C}(\mathrm{OEt})_{2}\right)_{2}(2 \mathrm{eq})$ $\mathrm{PhMe},-30^{\circ} \mathrm{C}, 16 \mathrm{~h}$

(c) $\mathrm{HCl}(3 \% \mathrm{aq}), \mathrm{THF}, \mathrm{rt}, 3 \mathrm{~d}$

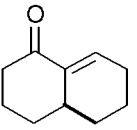

$56 \%$, er $>98: 2$
5 examples (combined yields $27-88 \%$, \%ee $=84-98 \%$ ).
The title reagent catalyses the substitition reaction of aryl chlorides with functionalised organozinc iodides.
B. H. Lipshutz, P. A. Blomgren, S.-K. Kim Tetrahedron Lett. 1999, 40, 197.
Dehydrogenative silylation of ketones with hydrosilanes in the presence of $\mathbf{A}$ with diethylamine and ethyl iodide as cocatalysts is described.
10 examples (yields 73-96\%) are reported.

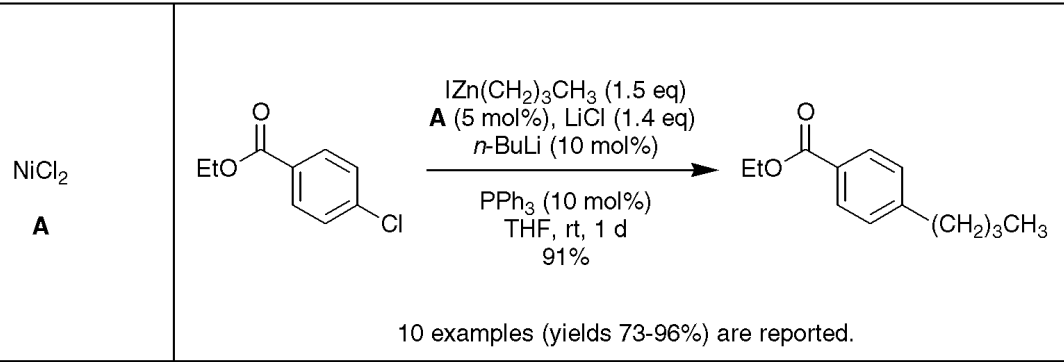

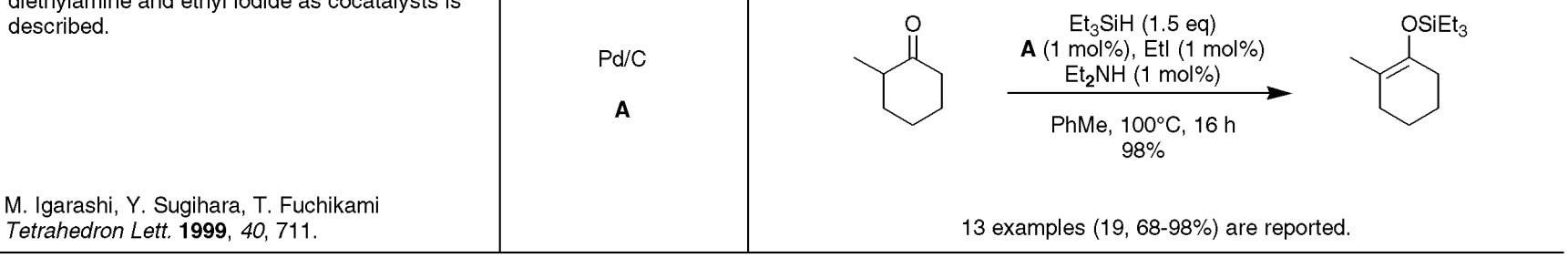


The title catalyst is used in the reaction of electron deficient olefins or imines with

substituted 2-alkynoates or 2,3-allenoates giving $[3+2]$ cycloaddition products.<smiles>CCOC(=O)C#CCP</smiles><smiles>CCC[C@@H]1C=C(OCC)C([PH+])[C@H]1c1ccccc1</smiles>

A

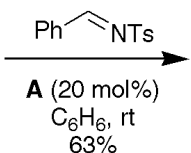

8 examples (yields $33-81 \%$ ), reactions performed with triphenylphosphine resulted in lower yields.

\begin{tabular}{l} 
Palladium/Carbon Ethylenediamine Complex \\
\hline $\begin{array}{l}\text { Partial hydrogenation of aromatic aldehydes and } \\
\text { ketones to benzylic alcohols has been achieved } \\
\text { using the title catalyst. }\end{array}$ \\
$\begin{array}{l}\text { H. Sajiki, K. Hattori, K. Hirota J. Chem. Soc., } \\
\text { Perkin Trans. 11998, 4043. }\end{array}$
\end{tabular}

\section{Chiral Phase Transfer Catalyst}

Catalyst

Phase-transfer catalysed asymmetric Darzens reactions of cyclic $\alpha$-chloroketones are reported.

S. Arai, Y. Shirai, T. Ishida, T. Shioiri Chem. Commun. 1999, 49.

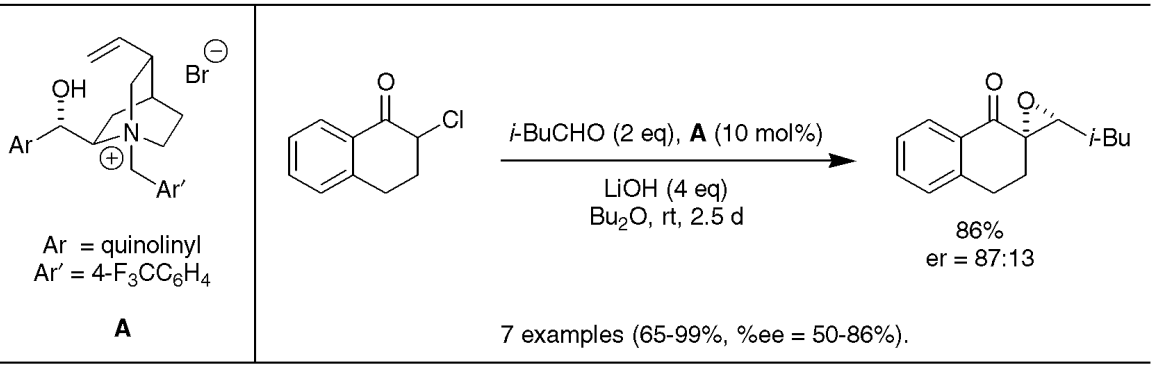

Dichloro(p-isopropyltolyl)ruthenium(II)

Catalyst

A convenient protocol for ring closing metathesis reactions is described. A solution of commercially available catalyst $\mathbf{A}$ and $\mathrm{PCy}_{3}$ is heated together with the diene substrate under neon light.

A. Fürstner, L. Ackermann Chem. Commun. 1999, 95. $\left[(p \text {-cymene }) \mathrm{RuCl}_{2}\right]_{2}$

A<smiles>C=CCOc1ccccc1CC=C</smiles>

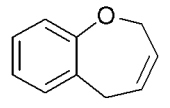
$\mathrm{CH}_{2} \mathrm{Cl}_{2}, \Delta, 16 \mathrm{~h}$

$78 \%$

9 examples (yields $65-90 \%$ ) are described.

\section{$\left[\mathrm{Ir}(\mathrm{cod})\left(\mathrm{PPh}_{2} \mathrm{Me}\right)_{2}\right] \mathrm{PF}_{6}$}

Iridium-catalysed isomerization of the double bond of 3-(silyloxy)-1-propenylboronates is reported. The methodology is utilised in the synthesis of $(\gamma$-(silyloxy)allyl)boronic esters.

Y. Yamamoto, T. Miyairi, T. Ohmura, N. Miyaura J. Org. Chem. 1999, 64, 296.
Catalyst

\begin{tabular}{c|c}
{$\left[\operatorname{lr}(\mathrm{cod})\left(\mathrm{PPh}_{2} \mathrm{Me}\right)_{2}\right] \mathrm{PF}_{6}$} \\
$\mathbf{A}$
\end{tabular}




\begin{tabular}{l|l|l}
\hline [Bis(tricyclohexylphosphine)benzylidene]ruthenium Dichloride & \\
\hline $\begin{array}{l}\text { The title compound catalyses the chemo- and } \\
\text { regioselective addition of chloroform across } \\
\text { mono- and 1,1-disubstituted olefins. }\end{array}$ & \\
\end{tabular}

The title reagent catalyses the enantioselective addition of diethylzinc to aromatic aldehydes.

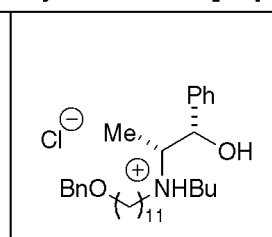

A

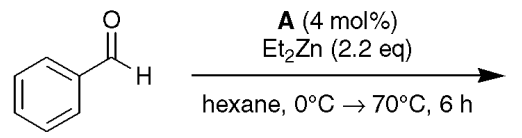<smiles>CC[C@H](O)c1ccccc1</smiles>

$95 \%$

er $=81: 19$

H. C. Hailes, J. Madden Synlett 1999, 105.

9 examples (yields 13-95\%, \%ee $=44-82 \%$ ).

\section{Bis[4R,5S)-4,5-diphenyl-1,3-oxazolin-2-yl]methane}

Ligand

Chiral titanium complexes prepared from the title ligand catalyse the enantioselective reduction of ketones in the presence of triethoxysilane.

M. Bandini, P. G. Cozzi, L. Negro, A.

Umani-Ronchi Chem. Commun. 1999, 39.

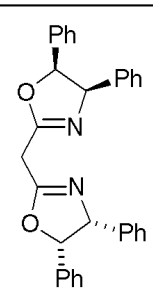

A<smiles>Cc1ccc(C(=O)CBr)cc1</smiles>

$\underset{\mathrm{THF}, \mathrm{rt}, 4 \mathrm{~d}}{\stackrel{\left[\mathrm{Ti}(\mathbf{A})_{2} \mathrm{~F}_{2}\right]}{(\mathrm{EtO})_{3} \mathrm{SiH}(2 \mathrm{eq})}}$<smiles>Cc1ccc([C@@H](O)CBr)cc1</smiles>

$61 \%$

er $=92: 8$

\section{Tri-tert-butylphosphine}

Ligand

A new catalyst system for the Heck coupling of aryl chlorides utilising $\mathbf{A}$ is reported.

A. F. Littke, G. C. Fu J. Org. Chem. 1999 $64,10$.
$\mathrm{H}_{2} \mathrm{C}=\mathrm{CHCO}_{2} \mathrm{Me}$ (2 eq)

$\mathrm{Pd}_{2}(\mathrm{dba})_{3}(1.5 \mathrm{~mol} \%)$

A (6 mol\%), $\mathrm{Cs}_{2} \mathrm{CO}_{3}(1.1 \mathrm{eq})$

Dioxane, $100^{\circ} \mathrm{C}, 42 \mathrm{~h}$<smiles>COC(=O)/C=C/c1ccccc1</smiles>

A

6 examples (yields $70-84 \%$ ) 
A vanadium catalyst derived from the title ligand is utilised in the asymmetric epoxidation of allylic alcohols.

N. Murase, Y. Hoshino, M. Oishi, H. Yamamoto $J$ Org. Chem. 1999, 64, 338 .

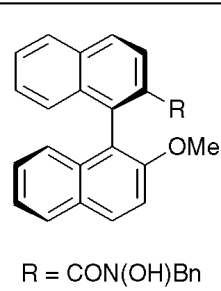

A

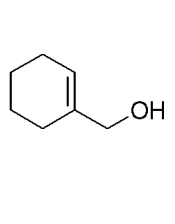

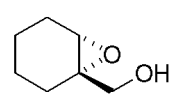

$61 \%$ er $=94: 6$

$\mathrm{VO}(\mathrm{Or})_{3}(5 \mathrm{~mol} \%)$

$\underset{\mathrm{PhMe},-20^{\circ} \mathrm{C}, 2 \mathrm{~d}}{\stackrel{\mathrm{Ph}}{3} \mathrm{COOH}(1.5 \mathrm{eq})} \longrightarrow$

Prop-2-ynyloxy carbonyl (POC) Group
The prop-2-ynyloxy carbonyl (POC) function,
can be cleaved under mild and neutral
conditions. The protecting group is stable to both
acidic and basic conditions.
S. Sinha, $\mathrm{P}$. Ilankumaran, $\mathrm{S}$. Chandrasekaran
Tetrahedron Lett. 1999, 40,771.

4-Acetylamino-2,2,6,6-tetramethylpiperidine-1-oxoammonium Perchlorate

Reagent

The readily prepared, stable, nonhygroscopic title compound is used in the oxidation of alcohols to ketones or aldehydes. The reaction is

colorimetric, does not require anhydrous conditions, and the oxidant can be easily regenerated.

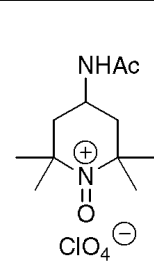

A<smiles>CC(C)=CCCC(C)=CCO</smiles>
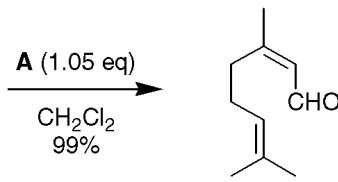

20 examples (yields $96-100 \%$ )
The title compound mediates a modified Lossen rearrangement in which no Lewis acid is required. The reaction proceeds with retention of configuration of the migrating group. Suh, P. L. Feldman J. Org. Chem. 1998, 63 10040 .

$$
\begin{aligned}
& \lambda_{\mathrm{O}^{-}}^{\mathrm{O}} \|_{\mathrm{H}^{-}} \\
& \text {A } \\
& 69 \%
\end{aligned}
$$

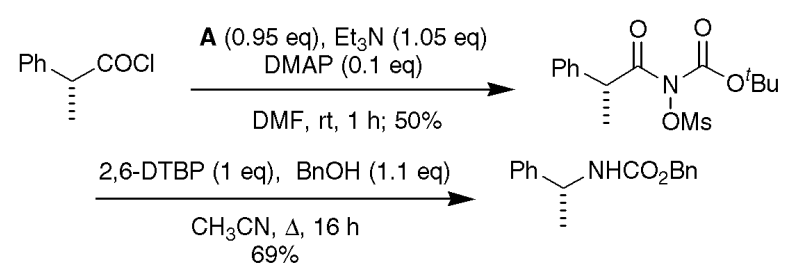

4 examples using $\mathbf{A}$ (yields $43-82 \%$ ) and 8 examples using different alcohols or amines (yields $53-81 \%$ ) are reported.

\section{Dimethyldioxirane}

Reagent

The oxidation of nitronate anions generated from the corresponding nitroalkanes using the title reagent is described, providing a mild and

efficient alternative to the traditional Nef reaction. Zhao Synlett 1998, 1335 


\begin{tabular}{l}
\hline Bis(bromozincio)methyltrimethylsilane \\
\hline $\begin{array}{l}\text { The olefination of aldehydes and ketones using } \\
\text { the title reagent in combination with titanium(II) } \\
\text { chloride is described. }\end{array}$ \\
\begin{tabular}{l|l|l} 
S. Matsubara, T. Mizuno, T. Otake, M. Kobata, K. \\
Utimoto, K. Takai Synlett 1998, 1369.
\end{tabular}
\end{tabular}

Hydroboration of trisubstituted olefins with $\mathbf{A}$ followed by treatment with $\mathrm{Et}_{2} \mathrm{BH}$ and $i-\mathrm{Pr}_{2} \mathrm{Zn}$ affords diastereomerically pure organozinc reagents which are trapped by various electrophiles with retention of configuration.

A. Boudier, F. Flachsmann, P. Knochel Synlett 1998,1438

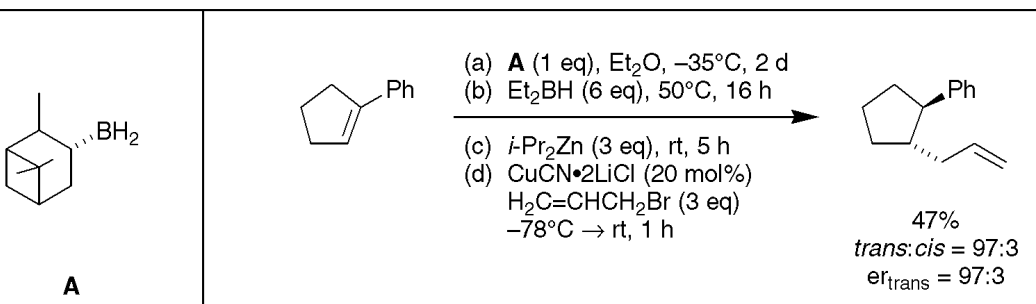

18 examples (yields $35-77 \%$, trans: cis $>97: 3, \%$ ee $=20-96 \%$ ) are described

The stereoselective synthesis of 2,4,6-trisubstituted tetrahydropyrans employing a Prins cyclisation and subsequent pinacol rearrangement is described.

M. J. Cloninger, L. E. Overman

M. J. Horvath, D. Saylik, W. R. Jackson, P. S. Elmes, C. G. Lovel, K. Moody Tetrahedron Lett. 1999, 40, 363.

\section{Diisopropylazodicarboxylate (DIAD)}

Adducts $\mathbf{A}$ and $\mathbf{B}$ derived from the title reagent are utilised in the preparation of alkyl and hindered aryl isocyanates from primary amines and carbon dioxide using Mitsunobu technology.

\section{9-Fluorenylmethylcloroformate}

The title reagent is used in the synthesis of 9 -fluorenylmethyl esters of $\mathrm{N}$-protected amino acids.

S. A. M. Mérette, A. P. Burd, J. J. Deadman Tetrahedron Lett. 1999, 40, 753.

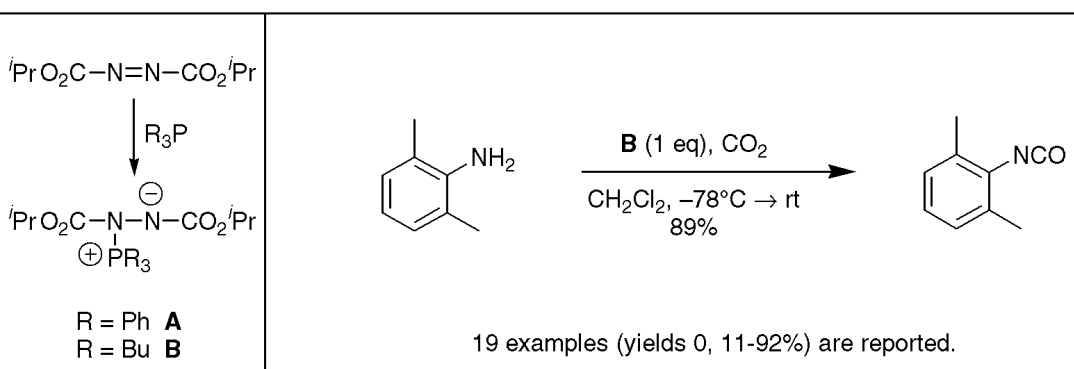

Reagent

7 examples (yields $50-81 \%, 2,4,6$-cis:2,6-cis, 4 -anti >6:1) 


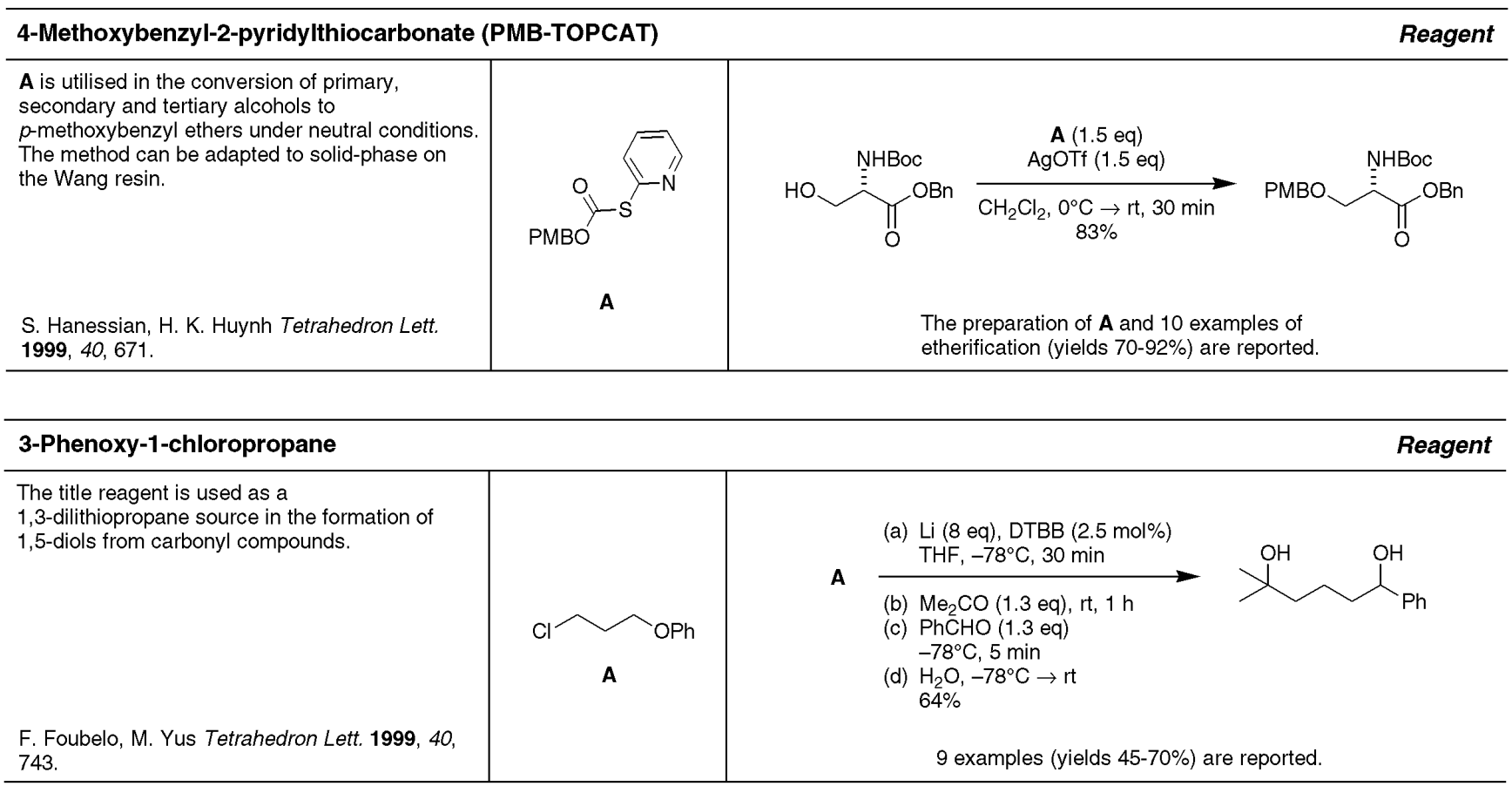

Trimethoxysilane

Reagent

The title reagent reduces hydroxyesters to diols in the presence of lithium methoxide. Lactones without a hydroxyl group and tosylimines are also reduced.

M. Hojo, C. Murakami, A. Fujii, A. Hosomi Tetrahedron Lett. 1999, 40, 911. 